\title{
利用表面模板调控低维有机纳米材料的拓扑结构
}

\author{
范其瑭 朱俊发 ${ }^{\star}$ \\ (中国科学技术大学, 国家同步辐射实验室和苏州纳米科学与技术协同创新中心，合肥 230029)
}

\begin{abstract}
摘要: “自下而上” 的纳米结构制备法是一种在原子或分子水平上构筑纳米结构的方法; 相比于“自上而下” 的蚀刻技术, 其可实现更小尺寸的半导体器件的制备。因此, 这种 “自下而上” 制备法将是纳米技术未来的 重要发展方向。然而, 其中一个存在已久的关键问题是如何实现对所构筑的纳米拓扑结构进行精确控制。此 文综述了近期关于如何调控由表面乌尔曼反应合成的纳米材料拓扑结构的研究。其中包括以下三个方面: 首 先, 利用纳米结构与祄底晶格参数之间的匹配关系控制金属有机链的形状; 其次, 利用超栅格或者超分子模 板对长链进行有效剪裁; 最后, 利用纳米结构与祄底之间对称性的匹配来调控环状和链状产物的形成。另外, 我们对寻求普适性模板以调控更广泛类型的纳米材料的拓扑结构进行了展望。
\end{abstract}

关键词: 结构调控; 表面模板; 乌尔曼反应; 表面合成; 金属有机; 聚合物; 大环分子 中图分类号: 0649

\section{Controlling the Topology of Low-Dimensional Organic Nanostructures with Surface Templates}

\author{
FAN Qi-Tang ZHU Jun-Fa \\ (National Synchrotron Radiation Laboratory and Collaborative Innovation Center of Suzhou Nano Science and \\ Technology, University of Science and Technology of China, Hefei 230029, P. R. China)
}

\begin{abstract}
The future of nanotechnology lies in the "bottom up" approach, which aims at building nanostructures at an atomic or molecular level so as to minimize the sizes of chips and other nano-devices. However, one of the long-term unresolved issues for "bottom up" nanotechnology is the precise control of the topologies of fabricated nanostructures. In this contibution, we review recent studies with regard to the control of the topologies of nanostructures formed via the on-surface Ullmann reaction of haloarenes. This includes three aspects: control of the shape of the organometallic chain via lattice matching between the adsorbate nanostructure and the substrate; tailoring the chains by employing super-gratings or supramolecular templates; and steering the covalent ring-chain competition in the reaction of precursors towards ring formation through adsorbate-substrate symmetry matching. Further, we present future directions for the development of more general templates for the regulation of the topologies of a broader range of nanostructures.
\end{abstract}

Key Words: Topology regulation; Surface template; Ullmann reaction; On-surface synthesis; Organometallic; Polymer; Macrocycle molecule

\footnotetext{
Received: January 12, 2017; Revised: March 10, 2017; Published online: April 7, 2017.

*Corresponding author. Email: jfzhu@ustc.edu.cn; Tel: +86-551-63602064.

The project was supported by the National Natural Science Foundation of China (21473178) and National Key Basic Research Program of China (973) (2013CB834605).

国家自然科学基金项目(21473178)和国家重点基础研究发展规划项目(973) (2013CB834605)资助

(C) Editorial office of Acta Physico-Chimica Sinica
} 


\section{Introduction}

The last decade has seen the prosperity of "top-down" techniques like lithography applied in semiconductor manufacturing industry. However, this technique will soon reach its limit due to quantum size effect, thus the future of nanotechnology should lie in the "bottom up" approach ${ }^{1}$. One of the ultimate goal of the "bottom up" nanotechnology is to build the so-called "molecular chip", that is, all the components in the chip are based on single or several molecules, which includes molecular wires, transistors, capacitors and $\mathrm{etc}^{2,3}$. In order to allow a considerable carrier transportation within the chip, covalent connections should be established between these components ${ }^{4}$. The organic chemistry has shed light on the realization of this goal due to diverse organic reactions that can be employed for covalent linking of versatile organic building blocks, including Ullmann, glaser, or dehydrogenative couplings ${ }^{5}$. Up to date, with specially designed and functionalized precursors, macromolecular structures with topological diversity and complex functions have been achieved directly on metal surfaces in ultrahigh vacuum (UHV) conditions. This includes graphene ${ }^{6-9}$ or graphyne ${ }^{10-13}$ derivatives, covalent/ organometallic linear polymers ${ }^{14-24}$ or cyclic rings ${ }^{25,26}$.

Typically, the controlling of the dimensions of the formed macromolecular nanostructure can be achieved by using precursors with different number of the reactive groups (i.e., halogen, alkynyl). For instance, the two-fold and multi-fold (three-fold or higher) halogen substituted haloarenes typically undergo Ullmann coupling into one-dimensional (1D) $)^{19,25,27}$ and two-dimensional (2D) $)^{9,20,21,28-31}$ polyphenylenes, respectively. In particular, the widths of the 1D chains can be regulated directly by the sizes of the precursors. This is evidenced by the synthesis of 1D graphene nanorribons with different widths from haloarenes with different sizes ${ }^{6,7,32}$. Additionally, the edge topology of the graphene nanoribbons can be steered into armchaired or zigzag shape by means of geometry design of the precursors $^{8}$. So far, the lengths of $1 \mathrm{D}$ chains obtained via

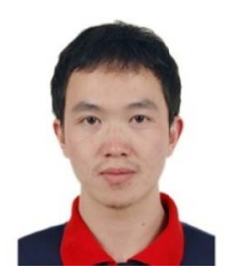

FAN Qi-Tang, received his Bachelor of Science in Physics from Nanchang University in 2011 and Ph.D of Engineering in Nuclear Science and Technology from University of Science and Technology of China (USTC) in 2016. He is currently working as a postdoctoral researcher in Philipps-Universität Marburg under the support of Humboldt Research Fellowship. His research interests focus on surface supramolecular assembly and on-surface synthesis of macromolecules. on-surface reactions mostly exhibit $\Gamma$-distribution due to the diffusion-controlled reaction process of precursors ${ }^{7,33,34}$. This raises an unresolved issue, i.e., how to control the chain length, which is of huge significance in the fabrication of molecular conducting wire with defined length.

Another interesting category of nanostructures is the cyclic polymers or macrocycles. The electronic properties of cyclic macromolecules are distinguished from their linear counterparts due to their endless topology, which may find new demands in the applications of molecular electronics ${ }^{35,36}$. Typically, the two-fold substituted precursor should react into 1D chains. Alternatively, the encounter of the two ends of a chain results in the formation of rings. However, the latter has seldom been observed due to the typical dominance of chain formation in ring-chain competition. Therefore, great challenge still remains in how to steer the ring-chain competition toward the direction of ring formation. To settle the above mentioned issues, we present several successful approaches in our recent studies for the topology regulation of $0 \mathrm{D}$ rings and $1 \mathrm{D}$ chains, including the ring size, chain length, and ring-chain competition. This is typically achieved by steering the reaction pathway of the precursors via multiple surface templates, as illustrated in Scheme 1. For instance, the lattice and symmetry matchings between the adsorbates and the templates have substantial influence on the toplogy of the formed nanostructures (Scheme 1(a, c)). The lengths of the chains can be unified and tuned by striped template, as shown in Scheme 1a. Additionally, the striped template can facilitate the formation of rings with tunable sizes due to the steric effect exerted therein (Scheme 1b). These initial success shed light on the developing of more general strategies for topology regulation of other macromolecular nanostructures, such as the size and shape of 2D networks as presented in Scheme 1d.

\section{Regulation of chain topologies}

Most of the organic reactions occurred on surfaces have

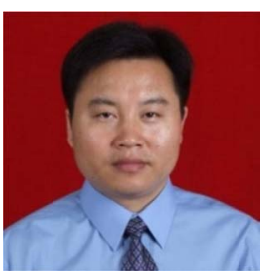

ZHU Jun-Fa, received his Ph.D. in Physical Chemistry from USTC in 1999. After several years working in the Institute of Experimental Physics, Johannes-KeplerUniversität Linz, Austria, Lehrstuhl für Physikalische Chemie II, FriedrichAlexander-Universität Erlangen-Nürnberg, Germany and Department of Chemistry, University of Washington, USA, he returned to USTC in December, 2006, and became a professor at National Synchrotron Radiation Laboratory, USTC under the support of "Hundred Talent Program" of Chinese Academy of Sciences. His research interests mainly focus on in-situ studies of surface chemistry and catalysis, surface/interface structures and properties of functional materials, and surface coordination chemistry. 


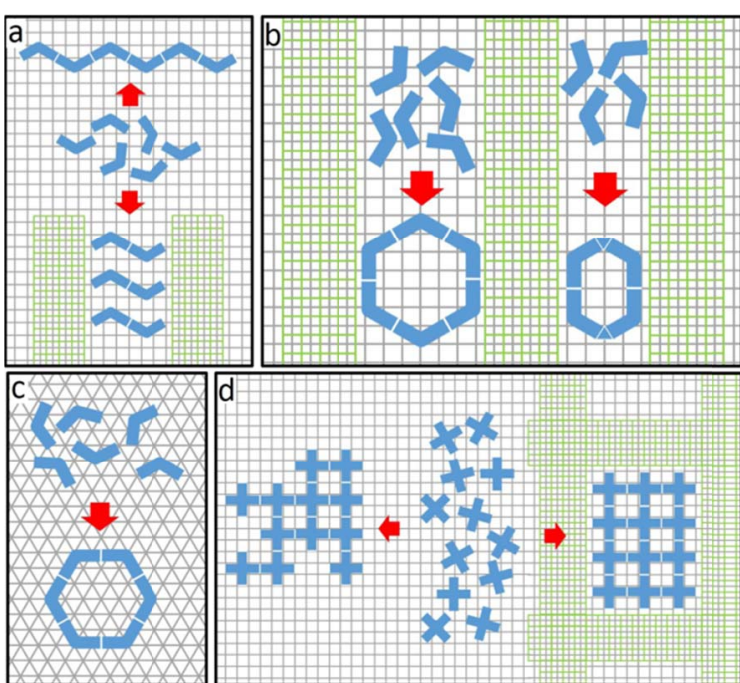

Scheme 1 Illustrations for the topology regulations of on-surface nanostructures with different surface templates.

(a) Bent precursors form six-membered (top) and two-membered (bottom) chains on flat and striped substrates, respectively. (b) Bent precursors form rings with tunable sizes determined by the widths of the stripes on the striped substrate.

(c) Bent precursors form rings on six-fold symmetric substrate due to symmetry matching. (d) Cross precursors form orthogonal networks with irregular and regular shape on flat and cross-patterned surfaces, respectively.

different pathways comparing to those in solution, especially when the surface plays a role as a template. In our recent works, the two-fold brominated 4,4"-dibromo- $m$-terphenyl (DMTP) molecules were employed for the fabrication of chains with different topologies on surfaces with different symmetries, i.e., $\mathrm{Cu}(111)$ and $\mathrm{Cu}(110)$. The deposition of submonolayer of DMTP molecules onto the six-fold symmetric $\mathrm{Cu}(111)$ at $300 \mathrm{~K}$ leads to the formation of exclusive zigzag organometallic chains with six orientations (marked with green arrows) as shown in Fig. $1 \mathrm{a}^{26}$. This indicates that the DMTP molecules has twelve optimal adsorption configurations on the $\mathrm{Cu}(111)$ surface. The detailed structure of the zigzag organometallic chains, which are composed of $m$-terphenyl (MTP) units connected by $\mathrm{C}-\mathrm{Cu}-\mathrm{C}$ bonds with all-trans configuration, is revealed by the molecularly resolved STM image overlaid with molecular model in Fig.1b. In addition, a periodicity of 2.65 $\mathrm{nm}$ along the chain has been measured.

However, the outcome is different on a two-fold symmetric $\mathrm{Cu}(110)$ surface. As shown in Fig.1c, organometallic chains with two different topologies (pointed with green and blue arrows) have been observed after deposition of submonolayer of DMTP onto $\mathrm{Cu}(110)$ held at $300 \mathrm{~K}^{27}$. The detailed structures of these two types of chain islands are revealed by their magnified views, as shown in Fig.1d and e. One type is the zigzag organometallic chain, which is similar to that formed on $\mathrm{Cu}(111)$ as illustrated by the overlaid molecular model in Fig.1d. However, the periodicity $(2.79 \mathrm{~nm})$ along the chain is larger than the chains formed on $\mathrm{Cu}(111)(2.65 \mathrm{~nm})$. This is most possibly due to the different lattice matching of the zigzag

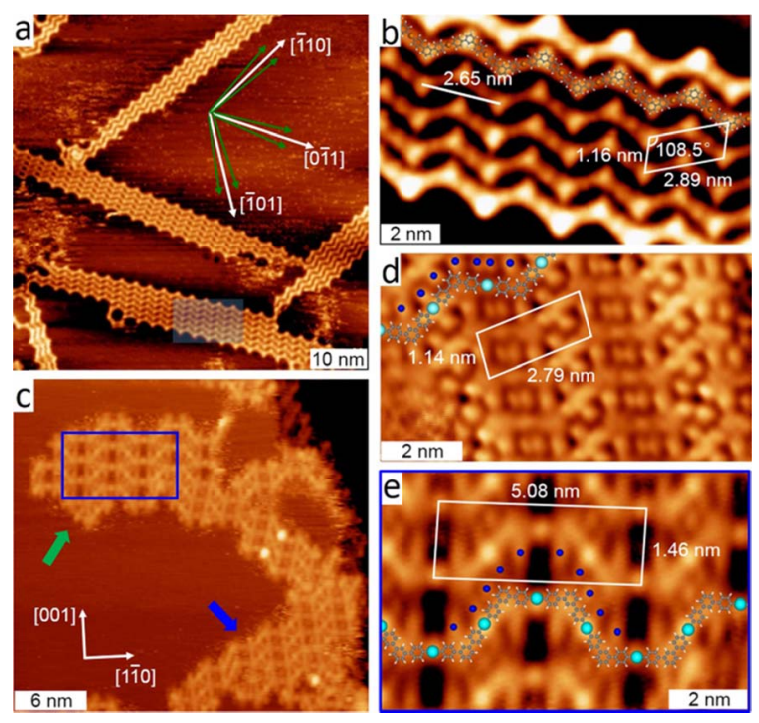

Fig.1 (a) Constant-current STM image taken after deposition of 4,4"-dibromo-m-terphenyl (DMTP) onto $\mathrm{Cu}(111)$ at $300 \mathrm{~K}$ at a coverage of $0.2 \mathrm{ML}$; tunneling parameters: $U=-3.6 \mathrm{~V}, I=0.02 \mathrm{nA}$.

(b) Higher-resolution image of the shaded area in panel (a) with overlaid molecular model and unit cell, $U=-3.6 \mathrm{~V}, I=0.01 \mathrm{nA}$. (c) STM image obtained at $300 \mathrm{~K}$ after 0.48 ML DMTP molecules were deposited onto $\mathrm{Cu}(110)$ at $300 \mathrm{~K} . U=-2.9 \mathrm{~V}, I=0.02 \mathrm{nA}$. (d) High resolution STM image of a section of the same all-trans zigzag structure as marked by blue arrow in (b), $U=-2.0 \mathrm{~V}, I=0.02 \mathrm{nA}$.

(e) Magnified view of the blue framed region in panel (b) showing the cis/trans chains, $U=-2.9 \mathrm{~V}, I=0.03 \mathrm{nA}$.

Gray spheres represent carbon atoms; whitte, hydrogen; brown and cyan, copper;

blue, bromine. Reproduced with permission from Refs.26,27. Copyright 2013 Wiley-VCH and Copyright 2016 the Royal Society of Chemistry.

chains with different surfaces. Moreover, only two orientations were observed for the zigzag organometallic chains formed on $\mathrm{Cu}(110)$, indicating four optimal adsorption configurations of the MTP unit. Again, this should result from the symmetry matching between the zigzag organometallic chains and the substrates. The other type is the trapezoidal-waved organometallic chains consists of $m$-terphenyl (MTP) units connected by $\mathrm{C}-\mathrm{Cu}-\mathrm{C}$ bonds with alternative cis/trans configuration, as shown in Fig.1e. The formation of trapezoidal-waved chain is the result of incorporation of MTP units with four optimal adsorption configurations into a single chain.

Similarly, the incorporation of MTP units on $\mathrm{Cu}(111)$ with six different optimal adsorption configurations enables the formation of "back-folding" organometallic chain or macrocycles as discussed below. Fig.2a shows the STM image after deposition of 0.55 monolayer (ML) DMTP onto $\mathrm{Cu}(111)$ at $300 \mathrm{~K}^{37}$. The encounter of zigzag organometallic chain domains at higher coverage leads to the formation of back-folding organometallic chains or cyclic organometallic oligomers around the domain broundaries (marked by white frames in Fig.2). As shown in Fig.2b, a cluster of three adjacent hexagons (MTP-Cu $)_{6}$ has been observed in the upper left region, 


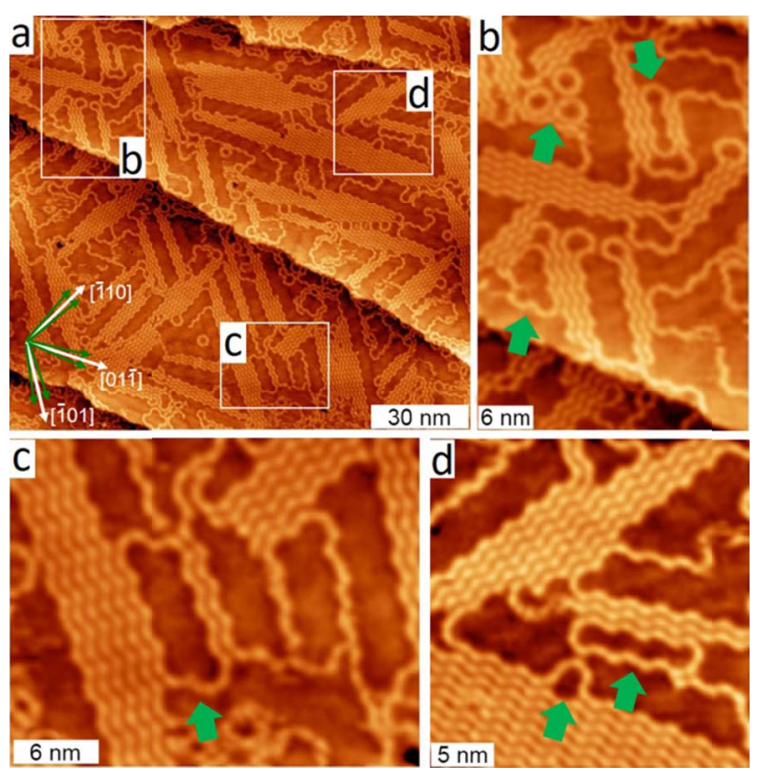

Fig.2 STM images of the organometallic oligomers and polymers obtained after deposition of 0.55 ML DMTP onto $\mathrm{Cu}(111)$ at $300 \mathrm{~K} ; U=-2.75 \mathrm{~V}, I=0.08 \mathrm{nA}$.

(a) overview STM image; (b) enlarged region of (a) with the macrocycles $(\mathrm{MTP}-\mathrm{Cu})_{6},(\mathrm{MTP}-\mathrm{Cu})_{14}$ and $(\mathrm{MTP}-\mathrm{Cu})_{16}$, as marked by green arrows;

(c) enlarged region of (a) with (MTP-Cu $)_{22}$ (green arrow); (d) enlarged region of (a) with the macrocycle (MTP-Cu) ${ }_{18}$ (green arrow). Reproduced with permission from Ref.37. Copyright 2014 American Chemical Society.

the formation of which can be reckoned as the encounter and connection of three (MTP-Cu$)_{2}$ oligomeric chains oriented along three directions with mutual angles of $120^{\circ}$. In such a case, the variation of lengths of the three oligomeric chains can lead to the formation of organometallic cycles with different shapes and sizes. This includes the macrocycles (MTP-Cu $)_{14}$ and (MTP-Cu $)_{16}$ on the right-hand and the lower part of Fig.2b, respectively. Also, larger macrocycles $(\mathrm{MTP}-\mathrm{Cu})_{22}$ and $(\mathrm{MTP}-\mathrm{Cu})_{18}$ were observed as shown in Fig.2c and $2 \mathrm{~d}$ (pointed with green arrows). Therefore, the formation of chains with different number of orientations and topologies on $\mathrm{Cu}(111)$ and $\mathrm{Cu}(110)$ strongly reflects the template role of the substrate during Ullmann reaction of DMTP monomers. Similar template effect has been observed for stepped surfaces which provide striped terraces to align the growth of polymer chains along the step edges ${ }^{10,38}$. Besides the surface corrugation, the nature of the substrate material also has significant influence on the formed nanostructures via Ullmann reaction. This is evidenced by the formation of $2 \mathrm{D}$ porous graphene network from cyclohexa-m-phenylene (CHP) monomer with different order and compactness on $\mathrm{Cu}(111), \mathrm{Ag}(111)$ and $\mathrm{Au}(111)$ surfaces ${ }^{9}$.

\section{Regulation of chain length}

Except from the regulation of the chain shapes mentioned above, the width of the chains was typically steered by employment of precursors with different sizes. For instance, the two-fold brominated linear 4,4"-dibromo- $p$-terphenyl monomer forms 1D polyphenylene chain with a width of three carbon atoms ${ }^{19}$. Additionally, the use of a wider two-fold brominated 1,4,5,8-tetrabromonaphthalene precursor leads to the formation of graphene nanoribbon with a wildth of five carbon atoms (i.e., 5 -armchaired graphene nanoribbon $(5-A G N R))^{32}$. Further increasing the width of the precursor, i.e., the employment of $10,10^{\prime}$-dibromo-9,9'-bianthryl, results in the formation of even wider 7 -AGNR. ${ }^{7}$ Nevertheless, the studies related to the regulation of the lengths of chains have seldom been reported. Typically, the 1D chains formed via on-surface synthesis exhibit a $\Gamma$-distribution as a result of the diffusion controlled assembly process, such as the formation of graphene nanoribbons on the $\mathrm{Au}(788)$ stepped surface ${ }^{34}$.

This case also ocurrs for organometallic chains acquired after deposition of DMTP onto both $\mathrm{Cu}(110)$ and $\mathrm{Cu}(111)$ surface. Fig.3a shows the islands of the zigzag organometallic chains obtained by deposition of 0.77 ML DMTP on $\mathrm{Cu}(111)$ at 440 $\mathrm{K}^{37}$. Although the size of the islands has been enlarged by applying a higher substrate temperature during deposition, the shapes of the islands remain irregular. This indicates that the lengths of the chains still follow certain distribution determined by their assembly process, as revealed by the magnified view of the island in Fig.3b. Similarly, increasing the tempreature of $\mathrm{Cu}(110)$ to $383 \mathrm{~K}$ during the deposition of DMTP leads to the formation of exclusive zigzag organometallic chains rather than the mixture of zigzag and trapezoidal-waved chains, as shown

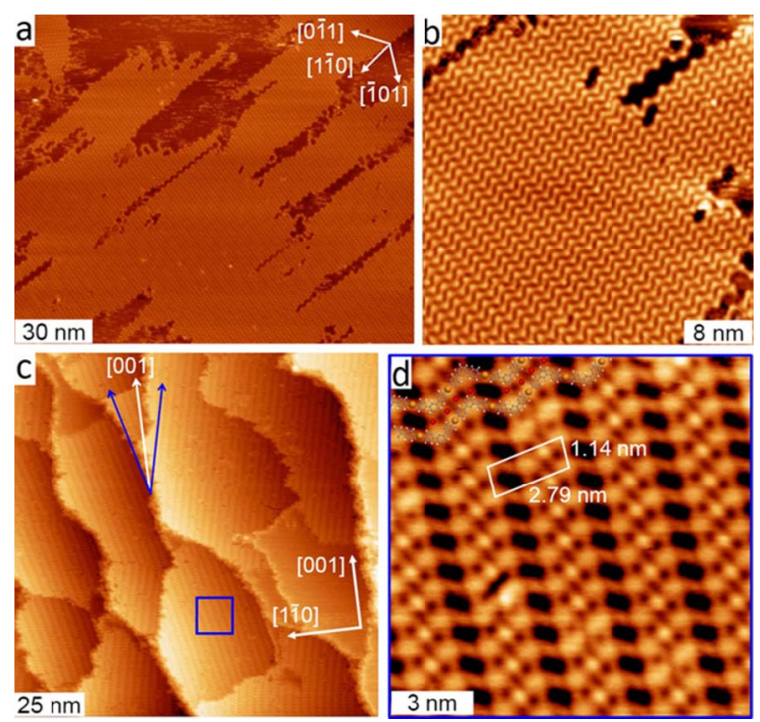

Fig.3 (a) STM image of large islands of the organometallic polymer obtained by deposition of 0.77 ML DMTP onto Cu(111) held at $440 \mathrm{~K} ; U=-3.6 \mathrm{~V}, I=0.01 \mathrm{nA}$. (b) Magnified image of the central area in (a), $U=-3.6 \mathrm{~V}, I=0.02$ nA. (c) Overview STM image taken after deposition of 0.77 ML DMTP onto $\mathrm{Cu}(110)$ held at $383 \mathrm{~K}$. (d) Zoom-in of the blue-framed region in panel (c) overlaid with the molecular model.

Gray spheres represent carbon atoms; white, hydrogen; brown, copper; red, bromine (color online). Reproduced with permission from Refs.37,39. Copyright 2014 and 2016 Ameriican Chemical Society. 
in Fig.3(c, d) ${ }^{39}$. This is most possibly due to that the zigzag chains are thermodynamically more stable than the trapezoidal-waved chains. Because the former has a higher packing density which would maxmize the mutual attractions between chains. Note that this interpretaion also explains the elimination of organometallic cycles on $\mathrm{Cu}(111)$ (Fig.3a) at 440 $\mathrm{K}$, which is also the less stable products due to their lower packing density comparing to the chains. The domains of zigzag organometallic chains formed on the $\mathrm{Cu}(110)$ surface also exhibit irregular shapes, which depend mostly on the shapes of the step edges.

In order to tailor the lengths of these zigzag organometallic chains, special template was employed to regulate the Ullmann reaction of DMTP monomers. The template is a supergrating surface, i.e., a $\mathrm{Cu}(110)-(2 \times 1) \mathrm{O}$ superstructure ${ }^{39}$. The supergrating template was prepared by an appropriate exposure of $\mathrm{Cu}(110)$ surface to $\mathrm{O}_{2}$ atmosphere at an elevated temperature. This procedure results in the formation of a submonolayer of $\mathrm{Cu}-\mathrm{O}$ chains on the $\mathrm{Cu}(110)$ surface. Therefore, the supergrating consists of alternatively arranged $\mathrm{Cu}-\mathrm{O}$ chain stripes and bare $\mathrm{Cu}$ stripes, both of which orient along the [001] direction. In addition, the widths of the bare $\mathrm{Cu}$ stripes can be adjusted by controlling the oxidation extent of $\mathrm{Cu}(110)$ : increasing the exposure of $\mathrm{O}_{2}$ at the same substrate temperature makes the bare $\mathrm{Cu}$ stripes narrower, whereas keeping the exposure constant but increasing the substrate temperature would result in broader $\mathrm{Cu}$ stripes and larger distances between them.

Fig.4a shows the overview STM image taken after deposition of $0.66 \mathrm{ML}$ DMTP onto the $\mathrm{Cu}(110)-(2 \times 1) \mathrm{O}$ surface composed of $\mathrm{Cu}$ stripes (with widths from 14 to $18 \mathrm{~nm}$ ) held at $383 \mathrm{~K}^{39}$. Domains of well-ordered short zigzag organometallic chains were observed on the bare $\mathrm{Cu}$ stripes. They are separated by $\mathrm{Cu}-\mathrm{O}$ stripes, which are imaged as darker stripes. Fig. $4 \mathrm{~b}$ shows the magnified STM image of a zigzag organometallic chain domain with a width of $16.6 \mathrm{~nm}$. The lengths of the chains in this domain can be calculated to be $18.2 \mathrm{~nm}$ according to their constant angle $\left(24^{\circ}\right)$ relative to the [001] direction. As can be seen, the long zigzag organometallic chains are tailored into short oligomeric chains with molecular accuracy. It should be noted that the successful tailoring of the zigzag organometallic chains with $\mathrm{Cu}(110)-(2 \times 1) \mathrm{O}$ striped surface requires the condition that the presence of the $\mathrm{Cu}-\mathrm{O}$ chains does not affect the registry of the zigzag organometallic chains with the $\mathrm{Cu}(110)$ surface lattice. This is evidenced by the observations that the two mirror domains of the zigzag organometallic chains formed on the $\mathrm{Cu}(110)-(2 \times 1) \mathrm{O}$ striped surface have the same orientations as the domains formed on the clean $\mathrm{Cu}(110)$ surface (marked with blue arrows in Fig.4a).

Another alternative approach for the regulation of chain length is steering the chain growth with supramolecular template rather than the substrate. It utilizes noncovalent binding supramolecular motifs to steer the formation of covalently bounded nanostructures, such as the metal-ligand
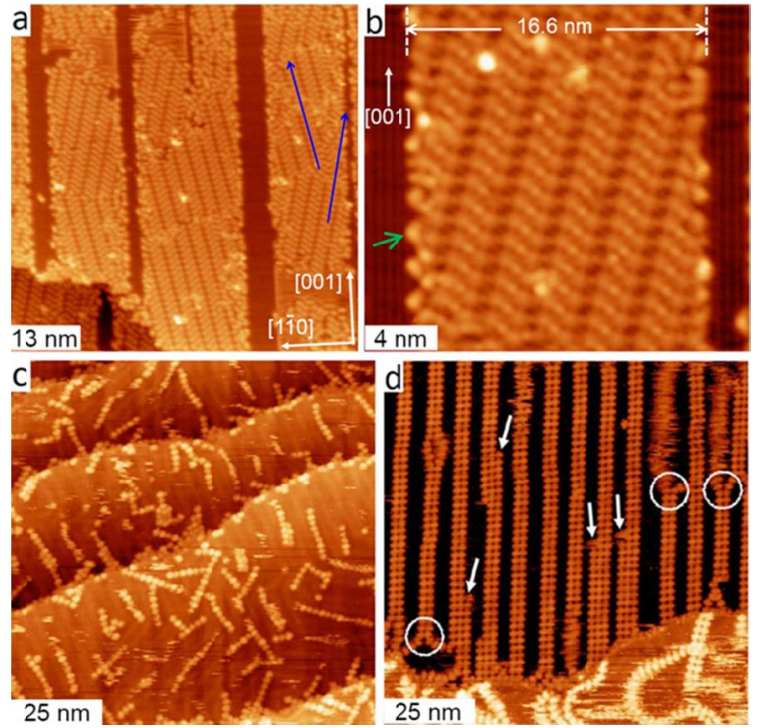

Fig.4 (a) STM image taken after deposition of 0.66 ML DMTP onto the $\mathrm{Cu}(110)-(2 \times 1) O$ striped surface $(\Theta 0=0.15 \mathrm{ML})$ held at $383 \mathrm{~K}$. (b) Magnified view of a region from the sample in panel (a). (c) STM image showing macromolecular structures formed from 5,15-bis(4'-bromophenyl)-10,20-bis(4'-phenyl)porphyrin on Au(111) (data acquired at $200 \mathrm{~K}$ ). (d) STM image of the sample prepared in two steps, where in each step,

5,15-bis(4'-bromophenyl)-10,2'0-bis(4'-pyridyl)porphyrin molecules deposited on the substrate at room temperature, annealed at $180^{\circ} \mathrm{C}$, and cooled down to room temperature.

Reproduced with permission from Refs.39,41. Copyright 2013 and 2016 American Chemical Society.

binding, hydrogen bonding, and even weaker $\pi-\pi$ interactions. This approach has been typically employed in solution synthesis and results in the acquirement of molecules with diverse topologies and properties that are otherwise difficult to achieve $\mathrm{e}^{40}$. Lin and co-authors have successfully transplanted this method to the metal surface, who employed a linear coordination template to control the on-surface polymerization ${ }^{41}$. As illustrated in Fig.4c, the polymerization of 5,15-bis(4'bromophenyl)-10,20-bis(4'-phenyl)porphyrin (DBDPP) on Au(111) surface under the assistance of copper leads to the formation of porphyrin chains with varied lengths, which again obey the $\Gamma$-distribution.

However, the deposition of 5,15-bis(4'-bromophenyl)-10, 20-bis(4'-pyridyl)porphyrin (DBDPyP) molecules with copper onto $\mathrm{Au}(111)$ at $180{ }^{\circ} \mathrm{C}$ resullts in the formation of the double-row (DR) dimeric chains with a high yield of $>60 \%$, as shown in Fig.4d. The DR chains consist of covalently linked porphyrin dimers which are then linked by pyridyl (Py) $-\mathrm{Cu}-$ pyridyl coordination bonds. The different outcomes stem from the modification of DBDPP molecule by replacing the two orthogonal phenyls with two pyridyl groups. This strongly indicates that the formation of long $\mathrm{Py}-\mathrm{Cu}-\mathrm{Py}$ bonded coordination chains steers the $\mathrm{C}-\mathrm{C}$ coupling reaction process. The reaction process can be described as follows: The growth 
of DR chains starts with the preliminary formation of covalently bounded porphyrin dimers. Then, in the intermediate state, the anchoring of two additional precursors were achieved by the formation of two $\mathrm{Py}-\mathrm{Cu}-\mathrm{Py}$ coordination bonds. In the final step, the anchored two precursors undergo $\mathrm{C}-\mathrm{C}$ Ullmann coupling forming the longer DR chain. Note that one requisite for the step-by-step growth of DR chains from the porphyrin dimer seeds is that they are stable during the annealing duration. This is guaranteed by the fact that the decomposition of DR chains requires breaking two metalligand bonds simultaneously, which is energetically very unfavorable. Therefore, Lin's work presents an effective approach for steering the lengths of covalent porphyrin chains by controlling the assembly kinetics via the coordination chain template with $\mathrm{Py}-\mathrm{Cu}-\mathrm{Py}$ bonds.

\section{Controlling of ring-chain competition}

One of the other significant aspects of the topology of macromolecule is their continuity, i.e., the cyclic topology. Typically, the chemical and physical properties of macromolecular/ polymer chain depend strongly on their terminal functional groups $^{42}$. In view of this, the properties of a chain should alter significantly if they undergo terminal encounter and covalent linkage into a cycle with terminal-free topology. This has been evidenced by numerous studies, in which the comparison of the properties of chains and their cyclic homologues reveals a huge difference between them. For instance, the cyclic polymers bear a higher density, lower intrinsic viscosity, and higher thermostability ${ }^{35,36,43-48}$. However, challenges still exist in controlling the formation of macrocycles and the characterization of their properties with powerful techniques. In this part, we will briefly review the studies concerning the steering of the ring-chain competition toward the direction of ring formation with special templates.

As discussed above, the deposition of DMTP onto clean $\mathrm{Cu}(110)$ surface at $383 \mathrm{~K}$ leads to the formation of exclusive zigzag organometallic chains. In order to steer the formation of organometallic rings, we have employed again the partially oxidized $\mathrm{Cu}(110)-(2 \times 1) \mathrm{O}$ surface as the template ${ }^{39}$. Nevertheless, the widths of the $\mathrm{Cu}$ stripes are in the range of 2.6 to $3.6 \mathrm{~nm}$. As shown in Fig.5a, the deposition of $0.22 \mathrm{ML}$ DMTP onto this template with narrow $\mathrm{Cu}$ stripes held at $383 \mathrm{~K}$ leads to the formation of organometallic tetragons (MTP-Cu $)_{4}$ (marked with green and white arrows) and hexagons $(\mathrm{MTP}-\mathrm{Cu})_{6}$ (marked with yellow arrow). Noteworthy, these species are typically not the single products obtained on $\mathrm{Cu}$ stripes with a particular width (other byproducts can be observed). However, the total yield of tetramers and hexamers on this surface reaches a high level comparing to that on the clean $\mathrm{Cu}(110)$ surface. Fig.5b shows the high-resolution STM image of a section of the cyclic organometallic tetragons $(\mathrm{MTP}-\mathrm{Cu})_{4}$, which consists of two cis-(MTP-Cu $)_{2}$ dimers linked by two bent $\mathrm{C}-\mathrm{Cu}-\mathrm{C}$ bonds as illustrated by the adsorption model in Fig.5c. The formation of extraordinary bent rather than straight bridges (marked with yellow ovals in Fig.5c) is mainly due to the strong spatial confinement effect imposed by $\mathrm{Cu}-\mathrm{O}$ chains, which is also proposed as the main stimulus for the formation of cyclic species.

Furthermore, the rotated but identical cyclic organometallic $(\mathrm{MTP}-\mathrm{Cu})_{4}$ tetragons are formed on the slightly wider $\mathrm{Cu}$ stripes with a width of $3.1 \mathrm{~nm}$. These tetragons bear an orientation perpendicular to that formed on $\mathrm{Cu}$ stripes with width of $2.6 \mathrm{~nm}$, as shown in Fig.5d. This change in the orientation is proposed to be driven mainly by a maximum utilization of the width of the wider $\mathrm{Cu}$ stripe $(3.1 \mathrm{~nm})$; otherwise additional MTP units would fill the remaining blank area of the wider $\mathrm{Cu}$ stripe. An additional increase of the width of $\mathrm{Cu}$ stripe to $3.6 \mathrm{~nm}$ results in the formation of the cyclic organometallic hexagons (MTP-Cu) $)_{6}$, as shown in Fig.5f. The corresponding adsorption model of these hexagons is displayed in Fig. 5 g, which can be regarded as formed by insertion of two additional MTP units (marked with white rectangles) into the left and right $c i s-(\mathrm{MTP}-\mathrm{Cu})_{2}$ dimers in the tetragon in Fig.5b. Therefore, by the employment of $\mathrm{Cu}(110)-(2 \times 1) \mathrm{O}$ surface with narrow $\mathrm{Cu}$ stripes $(2.6-3.6 \mathrm{~nm})$ as template, the organometallic ring-chain competition has been successfully steered towards the direction of ring formation. In addition, the sizes of the macrocyles can be tuned by the widths of $\mathrm{Cu}$ stripes.

Besides the organometallic case, competition of the formation of covalently ring-chain species has also been controlled by using effective template. As shown in Fig.6a, deposition of $0.84 \mathrm{ML}$ DMTP onto $\mathrm{Cu}(110)$ at $383 \mathrm{~K}$ followed by annealing at $458 \mathrm{~K}$ leads to the exclusive formation of

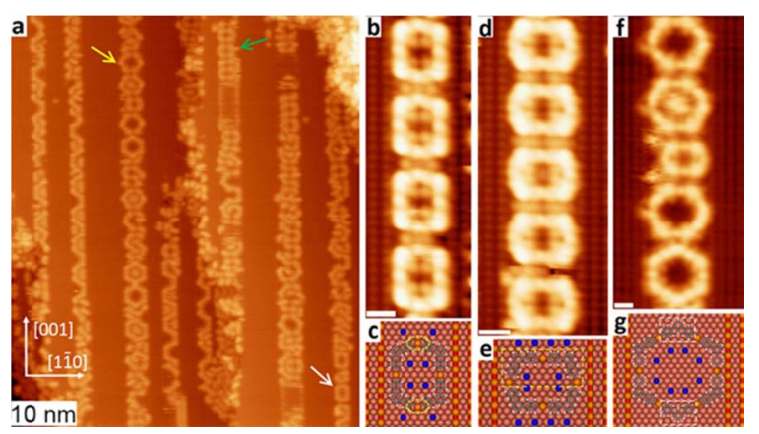

Fig.5 (a) Overview STM image taken after deposition of 0.22 ML DMTP onto Cu(110)- $(2 \times 1) O$ with a coverage of oxygen of $0.35 \mathrm{ML}$ held at $383 \mathrm{~K}$. The panels (b), (d) and (f) show the magnified view

of organometallic species formed on the sample in panel (a).

The corresponding molecular models are shown in (c), (e) and (g). (b, c) Tetramer (MTP-Cu) $)_{4}$ (d, e) Rotated tetramer (MTP-Cu) (f, g) Hexamer (MTP-Cu) 6 . Grey sp heres represent carbon atoms; white, hydrogen; blue, bromine; red, oxygen; coppery, copper atom. Tunneling parameters: (a) $U=0.6 \mathrm{~V}, I=0.07 \mathrm{nA}$; (b, d) $U=0.8 \mathrm{~V}, I=0.10 \mathrm{nA}$; (f) $U=0.5 \mathrm{~V}, I=0.07 \mathrm{nA}$. Reproduced with permission from Ref.39. Copyright 2016 American Chemical Society. 


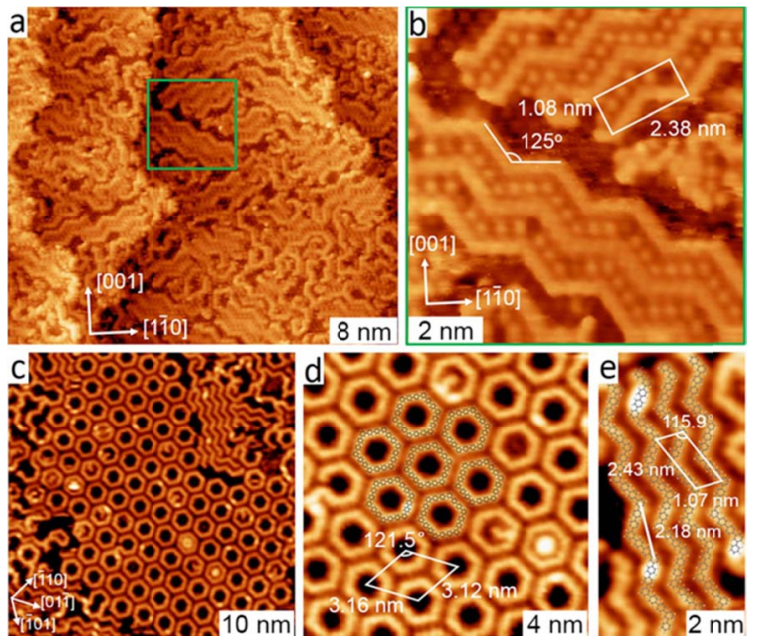

Fig.6 (a) Overview STM image taken after deposition of $0.84 \mathrm{ML}$ DMTP onto $\mathrm{Cu}(110)$ at $383 \mathrm{~K}$ followed by annealing at $458 \mathrm{~K}$, $U=-0.7 \mathrm{~V}, I=0.04 \mathrm{nA}$. (b) Zoom-in STM image of the green framed region in panel (b), $U=-1.5 \mathrm{~V}, I=0.06 \mathrm{nA}$. (c) Overview STM image obtained at $300 \mathrm{~K}$ after deposition of DMTP onto $\mathrm{Cu}(111)$ held at $550 \mathrm{~K}$. (d) Magnified view of the hyperbenzene island overlaid with molecular models and a unit cell. $U=-3.6 \mathrm{~V}$, $I=0.01$ nA. (e) Magnified view of a small section with oligophenylene chains.

Reproduced with permission from Refs.26,27. Copyright 2013 Wiley-VCH and Copyright 2016 the Royal Society of Chemistry.

domains of zigzag oligophenylene chains ${ }^{27}$. No cyclic species are observed on $\mathrm{Cu}(110)$. The high selectivity for chain formation is due mainly to the commensurability and the symmetry matching between the formed zigzag oligophenylene chains and the two-fold symmetric $\mathrm{Cu}(110)$ substrate. Fig.5b shows the magnified view of the zigzag oligophenylene chains, the unit cell of which is $1.08 \times 2.38 \mathrm{~nm}$. Notably, the newly formed zigzag oligophenylene chains are stretched along the chain direction. Thus, the angle of the bend (between two adjacent straight oligophenylene moiety) of the zigzag chains is calculated to be $125^{\circ}$. This stretching is most likely driven by adsorbate-substrate interactions and results in a better commensurability with the surface lattice.

However, the employment of the six-fold symmetric $\mathrm{Cu}(111)$ surface as the substrate during deposition of DMTP leads to the formation of oligophenylene rings with a high yield $^{26}$. As shown in Fig.6c, ordered arrays of hexagonal rings as the main products together with chain-like and other structures as minor products are obtained after deposition of DMTP onto $\mathrm{Cu}(111)$ at $550 \mathrm{~K}$. With the size and profile consideration, the hexagonal rings are verified as hyperbenzene consisting of six MTP units connected by $\mathrm{C}-\mathrm{C}$ bonds, as illustrated by the overlaid molecular model in Fig.6d. Comparing to the formation of exclusive two-fold symmetric zigzag oligophenylene chains on $\mathrm{Cu}(110)$, it is the six-fold symmetry of the $\mathrm{Cu}(111)$ substrate leads to the high selectivity of the reaction pathway with regard to the formation of hyperbenzene. Apart from the hyperbenzene arrays, zigzag oligophenylene chains (Fig.6e) are obtained as byproducts. Notably, their periodicity $(2.18 \mathrm{~nm})$ along the chain is considerably smaller than that of the oligophenylene chains $(2.38 \mathrm{~nm})$ formed on $\mathrm{Cu}(110)$ surface. This is due mainly to the different commensurabilities achieved between zigzag oligophenylene chains and the two different substrates. Therefore, the matching of the symmetries and lattice parameters between the covalent nanostructure and the substrate have huge impact on their growth kinetics, and thus can be employed to regulate their topologies.

\section{Conclusion and outlook}

In conclusion, in this paper we have reviewed recent works concerning the topology regulation of the nanostructures formed via on-surface reactions. First, the regulation of the shapes of organometallic chains is achieved by different lattice matching. As a result of the commensurability, the deposition of DMTP onto six-fold symmetric $\mathrm{Cu}(111)$ leads to the formation of exclusive zigzag organometallic chains. However, a mixture of zigzag and trapezoidal-waved organometallic chains forms on the two-fold symmetric $\mathrm{Cu}(110)$ under similar conditions. Second, the lengths of organometallic chains can be regulated by the super-grating or metal-directed supramolecular templates. By employing a $\mathrm{Cu}(110)-(2 \times 1) \mathrm{O}$ supergrating, the long zigzag organometallic polymeric chains are tailored into short oligomeric chains with uniform lengths, which can also be tuned via controlling of the width of grating. Additionally, the covalently bounded porphyrin chains are regulated into dimers with high yield by the formation of $\mathrm{Py}-\mathrm{Cu}-\mathrm{Py}$ coordination bonded chain templlate. Thirdly, the competition between the formation of covalent ring and chain from DMTP can be controlled by employing templates with different symmetries. DMTP forms exclusive zigzag oligophenylene chains on the two-fold symmetric $\mathrm{Cu}(110)$ surface, however, forms cyclic hyperbenzenes with high yield on the six-fold symmetric $\mathrm{Cu}(111)$ surface.

Although the topology of a certain category of organometallic or covalent chains can be controlled by several approaches presented in this review, huge challenges still remain in the application of these approaches to a wider range of $1 \mathrm{D}$ chains and $2 \mathrm{D}$ covalent networks. For instance, the currently used $\mathrm{Cu}(110)-(2 \times 1) \mathrm{O}$ supergrating template deconstructs when annealed with DMTP to $420 \mathrm{~K}$, and thus cannot be used to regulate the topology of covalently bounded nanostructures. To settle the potential similar issues, searching for diverse 1D and 2D supergrating surfaces that are more robust under the reaction of precursor monomersi is demanded. One possible example is the $1 \mathrm{D}$ supergrating formed by assembly of silicon nanowire on $\operatorname{Ag}(110),{ }^{49}$ although this may in return raise other issues concerning the interaction between the organic precursors and the supergratings. However, with the assistance of powerful surface science techniques, the further exploration of more general methods to steer the topologies of a broader 
range of nanostructures on surfaces is just a matter of time.

\section{References}

(1) Barth, J. V.; Costantini, G.; Kern, K. Nature 2005, 437, 671. doi: $10.1038 /$ nature 04166

(2) Champness, N. R. Nat. Chem. 2012, 4, 149. doi: $10.1038 /$ nchem. 1276

(3) Champness, N. R. Nat. Nanotechnol. 2007, 2, 671. doi: $10.1038 /$ nnano.2007.355

(4) Perepichka, D. F.; Rosei, F. Science 2009, 323, 216. doi: $10.1126 /$ science. 1165429

(5) Fan, Q.; Gottfried, J. M.; Zhu, J. Acc. Chem. Res. 2015, 48, 2484. doi: 10.1021/acs.accounts.5b00168

(6) Cai, J.; Pignedoli, C. A.; Talirz, L.; Ruffieux, P.; Sode, H.; Liang, L.; Meunier, V.; Berger, R.; Li, R.; Feng, X.; Müllen, K.; Fasel, R. Nat. Nanotechnol. 2014, 9, 896. doi: 10.1038/nnano.2014.184

(7) Cai, J.; Ruffieux, P.; Jaafar, R.; Bieri, M.; Braun, T.; Blankenburg, S.; Muoth, M.; Seitsonen, A. P.; Saleh, M.; Feng, X.; Muellen, K.; Fasel, R. Nature 2010, 466, 470. doi: 10.1038/nature09211

(8) Ruffieux, P.; Wang, S.; Yang, B.; Sánchez-Sánchez, C.; Liu, J.; Dienel, T.; Talirz, L.; Shinde, P.; Pignedoli, C. A.; Passerone, D.; Dumslaff, T.; Feng, X.; Müllen, K.; Fasel, R. Nature 2016, 531, 489. doi: $10.1038 /$ nature 17151

(9) Bieri, M.; Nguyen, M. T.; Groning, O.; Cai, J. M.; Treier, M.; Ait-Mansour, K.; Ruffieux, P.; Pignedoli, C. A.; Passerone, D.; Kastler, M.; Müllen, K.; Fasel, R. J. Am. Chem. Soc. 2010, 132, 16669. doi: $10.1021 / \mathrm{ja} 107947 \mathrm{z}$

(10) Cirera, B.; Zhang, Y. Q.; Björk, J.; Klyatskaya, S.; Chen, Z.; Ruben, M.; Barth, J. V.; Klappenberger, F. Nano Lett. 2014, 14, 1891. doi: $10.1021 / \mathrm{n} 14046747$

(11) Gao, H. Y.; Wagner, H.; Zhong, D.; Franke, J. H.; Studer, A.; Fuchs, H. Angew. Chem. Int. Ed. 2013, 52, 4024. doi: 10.1002/anie. 201208597

(12) Liu, J.; Chen, Q.; Xiao, L.; Shang, J.; Zhou, X.; Zhang, Y.; Wang, Y.; Shao, X.; Li, J.; Chen, W.; Xu, G. Q.; Tang, H.; Zhao, D.; Wu, K. ACS Nano 2015, 9, 6305. doi: 10.1021/acsnano.5b01803

(13) Zhang, Y. Q.; Kepcija, N.; Kleinschrodt, M.; Diller, K.; Fischer, S.; Papageorgiou, A. C.; Allegretti, F.; Björk, J.; Klyatskaya, S.; Klappenberger, F.; Ruben, M.; Barth, J. V. Nat. Commun. 2012, 3, 1286. doi: $10.1038 /$ ncomms 2291

(14) Di Giovannantonio, M. E. G., M.; Lipton-Duffin, J.; Meunier, V.; Cardenas, L.; Fagot Revurat, Y.; Cossaro, A.; Verdini, A.; Perepichka, D. F.; Rosei, F.; Contini, G. ACS Nano 2013, 7, 8190. doi: $10.1021 / \mathrm{nn} 4035684$

(15) Sun, Q.; Zhang, C.; Kong, H.; Tan, Q.; Xu, W. Chem. Commun. 2014, 50, 11825. doi: $10.1039 / \mathrm{c} 4 \mathrm{cc} 05482 \mathrm{~b}$
(16) Park, J.; Kim, K. Y.; Chung, K. H.; Yoon, J. K.; Kim, H.; Han, S.; Kahng, S. J. J. Phys. Chem. C 2011, 115, 14834. doi: $10.1021 /$ jp203129f

(17) Basagni, A.; Sedona, F.; Pignedoli, C. A.; Cattelan, M.; Nicolas, L.; Casarin, M.; Sambi, M. J. Am. Chem. Soc. 2015, 137, 1802. doi: $10.1021 /$ ja510292b

(18) Sun, Q.; Zhang, C.; Li, Z.; Kong, H.; Tan, Q.; Hu, A.; Xu, W. J. Am. Chem. Soc. 2013, 135, 8448. doi: 10.1021/ja404039t

(19) Wang, W. H.; Shi, X. Q.; Wang, S. Y.; Van Hove, M. A.; Lin, N. J. Am. Chem. Soc. 2011, 133, 13264. doi: 10.1021/Ja204956b

(20) Lafferentz, L.; Eberhardt, V.; Dri, C.; Africh, C.; Comelli, G.; Esch, F.; Hecht, S.; Grill, L. Nat. Chem. 2012, 4, 215. doi: 10.1038/nchem.1242

(21) Grill, L.; Dyer, M.; Lafferentz, L.; Persson, M.; Peters, M. V.; Hecht, S. Nat. Nanotechnol. 2007, 2, 687. doi: 10.1038/nnano.2007.346

(22) Chung, K. H.; Koo, B. G.; Kim, H.; Yoon, J. K.; Kim, J. H.; Kwon, Y. K.; Kahng, S. J. Phys. Chem. Chem. Phys. 2012, 14, 7304. doi: $10.1039 / \mathrm{c} 2 \mathrm{cp} 23295 \mathrm{~b}$

(23) Lipton-Duffin, J. A.; Miwa, J. A.; Kondratenko, M.; Cicoira, F.; Sumpter, B. G.; Meunier, V.; Perepichka, D. F.; Rosei, F. Proc. Natl. Acad. Sci. U. S. A. 2010, 107, 11200. doi: 10.1073/pnas.1000726107

(24) Zhong, D.; Franke, J. H.; Podiyanachari, S. K.; Blomker, T.; Zhang, H.; Kehr, G.; Erker, G.; Fuchs, H.; Chi, L. Science 2011, 334, 213. doi: $10.1126 /$ science. 1211836

(25) Lipton-Duffin, J. A.; Ivasenko, O.; Perepichka, D. F.; Rosei, F. Small 2009, 5, 592. doi: 10.1002/smll.200801943

(26) Fan, Q.; Wang, C.; Han, Y.; Zhu, J.; Hieringer, W.; Kuttner, J.; Hilt, G.; Gottfried, J. M. Angew. Chem. Int. Ed. 2013, 52, 4668. doi: 10.1002/anie. 201300610

(27) Dai, J.; Fan, Q.; Wang, T.; Kuttner, J.; Hilt, G.; Gottfried, J. M.; Zhu, J. Phys. Chem. Chem. Phys. 2016, 18, 20627. doi: 10.1039/C6CP03551E

(28) Gutzler, R.; Walch, H.; Eder, G.; Kloft, S.; Heckl, W. M.; Lackinger, M. Chem. Commun. 2009, 29, 4456. doi: 10.1039/b906836h

(29) Eichhorn, J.; Strunskus, T.; Rastgoo-Lahrood, A.; Samanta, D.; Schmittel, M.; Lackinger, M. Chem. Commun. 2014, 50, 7680. doi: $10.1039 / \mathrm{c} 4 \mathrm{cc} 02757 \mathrm{~d}$

(30) Fan, Q.; Wang, C.; Liu, L.; Han, Y.; Zhao, J.; Zhu, J.; Kuttner, J.; Hilt, G.; Gottfried, J. M. J. Phys. Chem. C 2014, 118, 13018. doi: $10.1021 /$ jp5037475

(31) Fan, Q.; Wang, T.; Liu, L.; Zhao, J.; Zhu, J.; Gottfried, J. M. J. Chem. Phys. 2015, 142, 101906. doi: 10.1063/1.4906214

(32) Zhang, H.; Lin, H.; Sun, K.; Chen, L.; Zagranyarski, Y.; Aghdassi, N.; Duhm, S.; Li, Q.; Zhong, D.; Li, Y.; Müllen, K.; Fuchs, H.; Chi, L. J. Am. Chem. Soc. 2015, 137, 4022. doi: 10.1021/ja511995r

(33) Han, P.; Akagi, K.; Federici Canova, F.; Mutoh, H.; Shiraki, S.; Iwaya, 
K.; Weiss, P. S.; Asao, N.; Hitosugi, T. ACS Nano 2014, 8, 9181. doi: $10.1021 / \mathrm{nn} 5028642$

(34) Linden, S.; Zhong, D.; Timmer, A.; Aghdassi, N.; Franke, J. H.; Zhang, H.; Feng, X.; Müllen, K.; Fuchs, H.; Chi, L.; Zacharias, H. Phys. Rev. Lett. 2012, 108, 216801. doi: 10.1103/PhysRevLett.108.216801

(35) Laurent, B. A.; Grayson, S. M. Chem. Soc. Rev. 2009, 38, 2202. doi: $10.1039 / \mathrm{b} 809916 \mathrm{~m}$

(36) Endo, K., Endo, K. Adv. Polym. Sci. 2008, 217, 121. doi: 10.1007/12_2008_157

(37) Fan, Q.; Wang, C.; Han, Y.; Zhu, J.; Kuttner, J.; Hilt, G.; Gottfried, J. M. ACS Nano 2014, 8, 709. doi: 10.1021/nn405370s

(38) Saywell, A.; Schwarz, J.; Hecht, S.; Grill, L. Angew. Chem. Int. Ed. 2012, 51, 5096. dio: 10.1002/anie.201200543

(39) Fan, Q.; Dai, J.; Wang, T.; Kuttner, J.; Hilt, G.; Gottfried, J. M.; Zhu, J. ACS Nano 2016, 10, 3747. dio: 10.1021/acsnano.6b00366

(40) Anderson, S.; Anderson, H. L. Templated Organic Synthesis; Wiley-VCH: Weinheim, Germany, 2000. doi: 10.1002/9783527613526.ch01

(41) Lin, T.; Shang, X. S.; Adisoejoso, J.; Liu, P. N.; Lin, N. J. Am. Chem. Soc. 2013, 135, 3576. doi: 10.1021/ja311890n

(42) Jia, Z.; Monteiro, M. J. J. Polym. Sci. A-Polym. Chem. 2012, 50, 2085. doi: 10.1002/pola.25999

(43) Zhang, K.; Tew, G. N. React. Funct. Polym. 2014, 80, 40. doi: 10.1016/j.reactfunctpolym.2014.01.012

(44) Yamamoto, T. Polym. J. 2013, 45, 711. doi: 10.1038/pj.2012.213

(45) Tezuka, Y. Polym. J. 2012, 44, 1159. doi: 10.1038/pj.2012.92

(46) Yamamoto, T.; Tezuka, Y. Polym. Chem. 2011, 2, 1930. doi: $10.1039 / \mathrm{clpy} 00088 \mathrm{~h}$

(47) Hoskins, J. N.; Grayson, S. M. Poly. Chem. 2011, 2, 289. doi: 10.1039/c0py00102c

(48) Kricheldorf, H. R. J. Polym. Sci. A-Polym. Chem. 2010, 48, 251. doi: $10.1002 /$ pola. 23755

(49) Sahaf, H.; Masson, L.; Léandri, C.; Aufray, B.; Le Lay, G.; Ronci, F. Appl. Phys. Lett. 2007, 90, 263110. doi: 10.1063/1.2752125 